\title{
Declining Use of the Hallervorden-Spatz Disease Eponym in the Last Two Decades
}

Lawrence A. Zeidman, MD, Dilip K. Pandey, MD, PhD

Department of Neurology and Rehabilitation, University of Illinois at Chicago Medical Center, Chicago, IL USA

\section{Declaration of conflicting interests:}

There were no conflicts of interest or commercial or other financial relationships of the authors.

\section{Funding:}

Funding for this project was supported entirely by inter-departmental funds.

\section{Acknowledgements:}

We wish to thank historian, Prof. Dr. Hans-Walter Schmuhl, of the University of Bielefeld, Germany, for reviewing the manuscript and offering feedback. Also thank you to Susanne Uebele, Archiv der Max-Planck-Gesellschaft, Berlin-Dahlem, for providing photographs of Hallervorden and Spatz. This work was done at the UIC Neurology Department, and was presented as a poster at the 2012 American Academy of Neurology meeting in New Orleans.

\section{Ethics Approval:}

N/A for this type of article given that no human research was performed

\section{Word Count for Manuscript:}

2,517 (not including title page, abstract, references, author roles, table, or figure legends)

\section{Address Correspondence to:}

Lawrence A. Zeidman, MD

University of Illinois at Chicago

Department of Neurology and Rehabilitation (M/C 796)

Neuropsychiatric Institute

912 S. Wood Street, Room $855 \mathrm{~N}$

Chicago, IL USA 60612-7330

Phone: 312-996-6496

Fax: 312-996-4169

Email: 1zeidm1@uic.edu 


\begin{abstract}
:
There has been a movement to rename Hallervorden-Spatz Disease to pantothenate kinase-associated neurodegeneration (PKAN) given the eponymous' complicity in murderous Nazi programs. Similar controversy surrounds Reiter syndrome, and two studies demonstrated decreased unqualified use of that eponym in the literature, but not in textbooks. There have been no similar studies regarding Hallervorden-Spatz Disease. We performed a MEDLINE search (1990-2010) looking for unqualified use of HallervordenSpatz Disease, and performed statistical analysis. We defined "unqualified" as having no reference to the eponym's disfavored use. We then looked in six neurology textbooks. We identified 156/278 articles $(56.1 \%)$ containing unqualified use of Hallervorden-Spatz Disease. But there was a declining trend $(p=0.000)$, with $70 / 80(87.5 \%)$ of articles from 1990-99, and 86/198 (43.4\%) from 2000-10. There was also decreased unqualified use of the eponyms in textbooks, with all recent editions using PKAN instead. The significant decrease in unqualified use of Hallervorden-Spatz Disease is reassuring.
\end{abstract}

\title{
Key Words:
}

Hallervorden-Spatz Disease, Pantothenate Kinase-Associated Neurodegeneration, Neurodegeneration with Brain Iron Accumulation, Neurological Eponyms, World War II 


\section{Introduction}

Much has been written in the neurology literature in the past two decades regarding the unethical activity during the Nazi "euthanasia" programs during World War II of two pre-eminent German neuropathologists, Julius Hallervorden (1882-1965) and Hugo Spatz (1888-1969). ${ }^{1-8}$ (Figure 1) From 1938-45, Hallervorden was Director of Neuropathology at the Kaiser Wilhelm Institute for Brain Research in Berlin-Buch, and Director of Pathology at the Brandenburg State Hospitals, which included the Brandenburg-Görden "euthanasia" killing center. ${ }^{3-5,8}$ At the same time, Spatz was Director of the Kaiser Wilhelm Institute for Brain Research and Hallervorden's superior. ${ }^{2,9}$ Between 1939 and 1941, Hallervorden actively collected and dissected brains of at least 697 murdered patients from the "euthanasia" programs. ${ }^{1-10}$ Hallervorden was well aware of the details of the euthanasia programs, and actively examined patients prior to their murders. ${ }^{3-5,8}$ Spatz was also complicit in the utilization of brains from the euthanasia programs. ${ }^{2,9}$

Hallervorden and Spatz in 1922 described the rare, autosomal recessive disorder that bears their name, Hallervorden-Spatz Disease, as follows: "It begins in the first decade with contractures of the legs and arms (particularly club feet), with following gait disturbances. The contractures proceed to other parts of the body (throat and neck). Choreoathetosis appears, as well as speech disturbances, hyperactive deep tendon reflexes and infantile behaviour. Other organs or systems are not involved in the disease process. Finally the patient dies because of a bronchopneumonia." 11 The neuropathological findings were globus pallidus and substantia nigra (zona reticularis) iron accumulation, without any structural changes in the basal ganglia or rest of the brain. 
They could not explain the neuropathological mechanisms causing these findings in the basal ganglia. ${ }^{12}$ In 2003, a call for Hallervorden-Spatz Disease to be renamed pantothenate kinase-associated neurodegeneration (PKAN) was made when the mutational defect on the pantothenate kinase 2 gene responsible for the majority of cases was elucidated, especially in light of the ethical controversy. ${ }^{13}$ Since that time, PKAN has been classified as one of three types of neurodegeneration with brain iron accumulation, the others being neuroferritonopathy and aceruloplasminemia. The other non-PKAN types of neurodegeneration with brain iron accumulation can be distinguished by lack of pantothenate kinase 2 gene mutation, different MRI appearance, and later clinical onset. ${ }^{12}$

Articles in $2005^{14}$ and $2008^{15}$ analyzed the trends in unqualified usage (ie, without mention of its disfavored use) of the Reiter Syndrome eponym in the medical literature since Reiter's unsavory past was uncovered. Dr. Hans Reiter (1881 - 1969) was known for his 1916 description of the post-infectious triad of arthritis, conjunctivitis, and urethritis that bears his name. But he was also president of the Nazi Reich Health Office in Germany, and authorized experiments on concentration camp victims during World War II, including one in which 250 Buchenwald concentration camp inmates died following typhus inoculations. ${ }^{14-15}$ Because of his war crimes and unethical activities, multiple articles since 1977 called for the renaming of Reiter Syndrome to Reactive Arthritis. In 2003, a group of rheumatology journal editors decided not to use the eponym in their journals anymore. ${ }^{14-15}$ Unqualified use of the term Reiter syndrome decreased from $57 \%$ to $34 \%$ from 1998 to 2003 (p=.001), ${ }^{14}$ and from $17.6 \%$ to $8.96 \%$ from 2003 to $2007(\mathrm{p}=.034),{ }^{15}$ but the term was still highly used in textbooks $(13 / 14) .{ }^{15}$ There have been no studies analyzing unqualified use of the Hallervorden-Spatz Disease eponym in 
medical journals or in popular neurology textbooks thus far. In this article, we sought to ascertain such trends in use of the term Hallervorden-Spatz Disease over the last two decades.

\section{Methods}

To select and identify articles, we performed a MEDLINE search (1990-2010) for English Language articles with keywords "Hallervorden-Spatz Disease" or "Hallervorden-Spatz Syndrome," auto-exploded to include "pantothenate kinaseassociated neurodegeneration" and "neurodegeneration with brain iron accumulation." We found a total number of articles during these two decades. Then, similar to Lu and Katz, ${ }^{14}$ we defined articles with unqualified use of Hallervorden-Spatz Disease or Hallervorden-Spatz Syndrome as articles that did not mention the ethical controversy surrounding the eponym, or the eponym's disfavored use. Some articles only used the term PKAN or neurodegeneration with brain iron accumulation, without mentioning the Hallervorden-Spatz Disease or Hallervorden-Spatz Syndrome eponyms, and those were not included in our tally of unqualified articles either. The percentage of articles with unqualified use of the eponyms out of the total number of articles on Hallervorden-Spatz Disease or Hallervorden-Spatz Syndrome within each year was calculated. We then attempted statistical analysis and looked for a trend in proportion over time for unqualified use of Hallervorden-Spatz Disease or Hallervorden-Spatz Syndrome. We used STATA software version 11. We performed a nonparametric test for a trend across ordered groups, ${ }^{16}$ which is an extension of the Wilcoxon rank-sum test. We then searched through the index of six popular English language neurology textbooks to identify the 
above mentioned eponyms. We chose the Textbook of Clinical Neurology, Adams and Victor's Principles of Neurology, Neurology in Clinical Practice, Merritt's Neurology, Greenfield's Neuropathology, and Brain's Diseases of the Nervous System. Where possible, we tried to include at least three editions of the textbooks, spanning the last two decades.

\section{Results}

Out of total of 278 articles identified, there were 156 articles (56.1\%) containing unqualified use of the eponyms (Table 1). From 1990-99, 70/80 (87.5\%) of the articles, and from 2000-10, 86/198 (43.4\%) of the articles, contained unqualified use. The test in proportion over time from 1990-2010 indicated a declining trend in unqualified use of the eponyms $(p=0.000)($ Figure 2$)$. When searching through the popular textbooks above, we found that only the most recent editions of four of them contained the more accurate term PKAN, or use of the Hallervorden-Spatz Disease eponym with qualification (Table 1). Two of the textbooks had qualified use of the Hallervorden-Spatz Disease eponym (mentioning the ethical controversy) in the last two editions (Neurology in Clinical Practice in 2004 and 2008, and Merritt's Neurology in 2005 and 2010). Overall, this data suggests a trend toward decreased use of the Hallervorden-Spatz Disease and Hallervorden-Spatz Syndrome eponyms in popular neurology textbooks as well.

\section{Discussion}


The results indicate a declining trend in unqualified use of the Hallervorden-Spatz Disease and Hallervorden-Spatz Syndrome eponyms over the past two decades, in both the medical literature and in neurology textbooks. This is consistent with the results seen in similar studies regarding unqualified use of the Reiter eponym. ${ }^{14-15}$ It seems after the landmark 2003 article by Hayflick et al, ${ }^{13}$ and the accompanying editorial by Shevell, ${ }^{8}$ unqualified use of Hallervorden-Spatz Disease or Hallervorden-Spatz Syndrome decreased the most. For 2003 the unqualified usage was 52.2\%, but thereafter trended down and was below $20 \%$ in 2008 . It is difficult to ascertain simply from these statistics whether unqualified use has decreased simply because of better global recognition after publication in a high impact journal of the ethical controversy of the eponym and the call to remove the Hallervorden-Spatz Disease eponym, or whether more investigators and authors now recognize the specific pathogenic cause of PKAN, or if it is related to the availability of an alternative easily recalled name (PKAN), or some combination of the above. Regarding neurology textbooks, the most recent editions of all six have qualified use of Hallervorden-Spatz Disease, or use PKAN, consistent with the literature. These recent editions were all published after 2007, though Merritt's Neurology (2005) and Neurology in Clinical Practice (2004) stopped using the eponyms earlier than the other four. The authors' conservative attitudes, or the fact that in some textbooks the chapters are copied verbatim in each edition, may explain the "lag-time" in textbooks to acknowledge the controversy compared to medical journals. ${ }^{15}$

The use of eponyms in medical literature is convenient, allows us to recognize the history and founders of the various specialties, is part of the initiation into the medical profession, and it conveys respect and admiration for all time to practitioners thus 
honored with them. ${ }^{8}$ Hallervorden and Spatz's landmark description of PKAN was worthy of admiration, but there is no doubt as to Hallervorden's later active complicity in Nazi medical crimes during World War II. U.S. Army Major and medical crimes investigator, neuropsychiatrist Leo Alexander, MD (himself a German-speaking refugee from Nazi Europe), interviewed Hallervorden after the war and wrote "Dr. Hallervorden himself initiated the collaboration. As he [Hallervorden] put it, 'I heard that they were going to do that, and so I went up to them and told them, 'Look here now, boys. If you are going to kill all those people, at least take the brains out so that the material can be utilized.' 'They asked me: 'How many can you examine?' And so I told them an unlimited number — the more the better.' 'There was wonderful material among those brains, beautiful mental defectives, malformations and early infantile diseases.' 'I accepted the brains, of course. Where they came from and how they came to me was really none of my business. ${ }^{\prime 9}$ It is quite clear that Hallervorden was only minimally concerned about the welfare of the patients who were murdered, and more concerned about the scientific value of the brains he actively collected.

Alexander also interviewed Spatz around the same time, who "denied that he or any member of his Institute ever received any [brains from the killing centers of the insane]. He added that the killing of the insane was done in deep secret, that nobody was supposed to know about it except SS [Schutzstaffel, Nazi paramilitary faction] personnel (although of course it did leak out), that consequently no scientists or scientific institutions could be contacted in order to undertake neuropathological studies, and that thus invaluable material was lost and remained unutilized." ${ }^{9}$ It is obvious from this statement that Spatz saw no ethical qualms with using brains from murdered patients, but 
states the Kaiser Wilhelm Institute for Brain Research wasn't involved. Hughes ${ }^{2}$ makes a point that Spatz, as director of the Kaiser Wilhelm Institute for Brain Research could not have been unaware of the brains arriving in large "batches of $150-250$ at a time." The elaborate examination of Hallervorden's 697 brains would have been an enormous addition to the other work of the Kaiser Wilhelm Institute for Brain Research. ${ }^{2}$ Neuropathologist and historian Jürgen Peiffer analyzed all records from Spatz's Department of Neuroanatomy in Berlin and found that 105 brains studied from various hospitals and clinics were either certainly or very probably from euthanasia victims. ${ }^{10}$ Thus it becomes clear that for Hallervorden and Spatz "the quest for scientific discovery had become an all-consuming passion.” They were so blinded by ambition and intellectual curiosity that they could not see the bigger picture that their work lent moral legitimacy to Nazi programs. ${ }^{3,17}$ Indeed, the work of pre-eminent neuroscientists justified the murder even further than eugenics (racial "hygiene" theories) ${ }^{2,4}$ As a profession, the continued homage via an eponym toward Hallervorden and Spatz is unacceptable. The downward trend in unqualified use of the Hallervorden-Spatz Disease eponym in neurology textbooks and the medical literature is reassuring.

Why did it take so long for the controversy surrounding the Hallervorden-Spatz Disease eponym to arise? The unethical nature of Hallervorden's use of brains from murdered patients was published in the New England Journal as early as $1949,{ }^{18}$ and was intensely debated as early as 1946-7 at the time of the Nuremberg Doctors' Trial of Nazi physicians. There was also much controversy and debate in 1953 regarding whether Hallervorden should be invited as a speaker at the $5^{\text {th }}$ International Congress of Neurology in Lisbon. ${ }^{10}$ At the time, Alexander wrote, "Unfortunately, he is thoroughly 
compromised by initiating collaboration with the killing centers for the insane, epileptica, and other chronic neuro-psychiatric patients in Germany. His own testimony corroborates this fact. This he freely volunteered at a time when he obviously did not realize that anyone would take issue with his attitude [at the end of the war in 1945]... He later chose to simply deny his responsibility, and thus he has never expressed regret or repentance or anything else that may re-establish his eligibility to a medical group founded on the common ground of ethical purposes the medical world has been based on for many centuries..." ${ }^{19}$ Belgian neuroscientist C.G.J. Rademecker wrote, "By accepting and examining these cerebrae he [Hallervorden] has furnished a soi-distant scientific excuse to the medical murderers, to the doctors, murdering the poor insane and others. By doing so he was a collaborator. Is that not sufficient? Would you not have been disgusted by the projection of the slides of these brains and would you at the end of his communication have applauded Hallervorden instead of protesting vehemently? The excuse of Hallervorden: "weil eine strikte Ablehnung dem Hirnforschunginstitut hätte schaden können" [because a strict refusal would have brought harm to the Brain Research Institute] is no excuse at all. When the Germans dismissed our Jewish colleagues the whole staff of the Leiden University [in Holland] resigned and all our laboratories etc. were closed..."19 As a consequence of the debates at this time, Hallervorden maintained some respect in Germany among colleagues, but was mostly ostracized on an international level. ${ }^{10}$ Additionally, numerous articles in the English neurology literature beginning in $1992,{ }^{3}$ and continuing through this past decade $e^{1,2,4-8,20}$ have addressed the controversy. The reason for the large gap in time in addressing the ethical controversy surrounding continued use of the Hallervorden-Spatz Disease eponym 
until the 1990s is unclear, but may have to do with an attempt to forget the crimes during the war and move on. But after Hallervorden and Spatz's deaths in the 1960s, as well as the re-emergence of Nazi data after the fall of the Berlin Wall in 1989, including almost 30,000 murdered patients' files and other documents, ${ }^{10}$ the time was ripe to renew concern about the Hallervorden-Spatz Disease eponym.

\section{Conclusions}

Just as in the case of Reiter, the crimes of Hallervorden and Spatz are heinous enough to warrant renaming Hallervorden-Spatz Disease, regardless of whether initially the eponym was well deserved. Their work lent moral legitimacy to Nazi plans, and the experience and success of the "euthanasia" programs is believed to have led to the Final Solution and murder of millions. ${ }^{21-22}$ The statistically significant trend toward decreased unqualified use of the Hallervorden-Spatz Disease and Hallervorden-Spatz Syndrome eponyms, as we have demonstrated, is a reassuring one. To continue to honor and immortalize the names of neuroscientists who abandoned the ethical principles upon which medicine was founded, and were accessories to mass murder, is unacceptable, especially if there are newer, more pathogenically accurate and easily recalled ways to describe a syndrome. However, abandoning the eponym entirely will prevent recognition of the ethical violations to future generations unaware of the crimes involved. Additionally and ironically, two Hallervorden-Spatz Disease patients were apparently victims of Nazi "euthanasia," ${ }^{23}$ thus entirely abandoning the eponym does not bring light to the crimes against them, and does them no honor. A better solution is likely to add "formerly," "previously," or "once known as" to eponyms of those who shouldn't be honored further 
(eg, "PKAN, formerly known as Hallervorden-Spatz disease"). ${ }^{6}$ This has already been done in recent articles. ${ }^{24-25}$ In this manner, neuroscientists guilty of unethical activity will no longer be remembered for their achievements, but for the crimes they committed. Hopefully, this will help prevent history from repeating itself, and the victims will be remembered appropriately. 


\section{References}

1. Cohen MM Jr. Genetic drift: overview of German, Nazi, and Holocaust medicine. Am J Med Genet A. 2010;152A(3):687-707.

2. Hughes JT. Neuropathology in Germany during World War II: Julius Hallervorden (1882-1965) and the Nazi programme of 'euthanasia'. J Med Biogr. 2007;15(2):116-122.

3. Shevell M. Racial hygiene, active euthanasia, and Julius Hallervorden. Neurology. 1992;42(11):2214-2219.

4. Shevell MI, Peiffer J. Julius Hallervorden's wartime activities: implications for science under dictatorship. Pediatr Neurol. 2001;25(2):162-165.

5. Shevell MI. Neurosciences in the Third Reich: from Ivory Tower to death camps. Can J Neurol Sci. 1999;26(2):132-138.

6. Kondziella D. Thirty neurological eponyms associated with the Nazi era. Eur Neurol. 2009;62(1):56-64.

7. Strous RD, Edelman MC. Eponyms and the Nazi era: time to remember and time for change. Isr Med Assoc J. 2007;9(3):207-214.

8. Shevell M. Hallervorden and History. N Engl J Med. 2003;348(1):3-4.

9. Alexander L. Combined Intelligence Objectives Sub-committee report: Neuropathology and Neurophysiology, Including Electro-encephalography, in Wartime Germany. Item No. 24, File No. XXVII-1. National Archives, Washington, DC, 1-65. 
10. Peiffer J. Assessing the Neuropathological Research carried out on Victims of the "Euthanasia" Programme. Med hist J. 1999;34;339-356.

11. Hallervorden J, Spatz H. Eigenartige Erkrankung im extrapyramidalen System mit besonderer Beteiligung des Globus pallidus und der Substantia nigra. Z Gesammte Neurolog Psychiatr. 1922;79:254-302.

12. Van Craenenbroeck A, Gebruers M, Martin J-J, Cras P. Hallervorden-Spatz Disease: Historical Case Presentation in the Spotlight of Nosological Evolution. Movement Disorders. 2010;25: 2486-2492.

13. Hayflick SJ, Westaway SK, Levinson B, Zhou B, Monique AJ, Ching KHL. Genetic, Clinical, and Radiographic Delineation of Hallervorden-Spatz Syndrome. N Engl J Med. 2003;348:33-40.

14. Lu DW, Katz KA. Declining use of the eponym "Reiter syndrome" in the medical literature, 1998-2003. J Am Acad Dermatol. 2005;53:720-723.

15. Keynan Y, Rimar D. Reactive Arthritis - The Appropriate Name. IMAJ. 2008;10:256-258.

16. Cuzick, J. 1985. A Wilcoxon-type test for trend. Statistics in Medicine. 4: 87-90.

17. Pross C. Nazi doctors, German medicine, and historical truth. In: Annas GJ, Grodin MA. The Nazi doctors and the Nuremberg Code: Human rights in human experimentation. Oxford: Oxford University Press; 1992. p. 32-52.

18. Alexander L. Medical science under dictatorship. N Engl J Med. 1949;241:39-47. 
19. MPG II 1A Pers. Hallervorden/5 [Personnel file, Hallervorden, at the Historical Archive of the Max-Planck-Gesellschaft, Berlin-Dahlem, Germany] in Peiffer J. Hirnforschung in Deutschland 1849 bis 1974. Berlin: Springer Verlag; 2004. p. 169-680.

20. Zeidman LA. Neuroscience in Nazi Europe Part I: Eugenics, Human Experimentation, and Mass Murder. Can J Neurol Sci. 2011;38(5):696-703.

21. Friedlander H. Toward the killing pause. In: The origins of Nazi genocide: from euthanasia to the final solution. Chapel Hill: University of North Carolina Press; 1995. p. $111-135$.

22. Proctor R. The destruction of "lives not worth living." In: Racial hygiene: Medicine under the Nazis. Cambridge, Mass: Harvard University Press; 1988. p. 177-222.

23. Eicke WJ. Neue Beobachtungen über die Hallervorden-Spatsche Krankheit. Archiv für Psychiatrie und Nervenkrankheiten. 1940;111:514-546.

24. Schrock LE, Ostrem JL. A Child With Progressive Dystonia, Dysarthria, and Spasticity. Rev Neurol Dis. 2010;7:39-42.

25. Kuo SH, Greene P. Clinical reasoning: A 16-year-old boy with freezing of gait. Neurology. 2010;75(6):e23-27.

\section{Author Roles:}

Lawrence A. Zeidman, MD - conception of the article, collection and analysis of data, authoring and editing the manuscript for submission

Dilip K. Pandey, MD, $\mathrm{PhD}$ - analysis of the data, statistical calculations, authorship of the manuscript 
Table 1. Frequency of Articles with Hallervorden-Spatz Disease or Syndrome over the past two decades (auto-exploded to include pantothenate kinase-associated neurodegeneration and neurodegeneration with brain iron accumulation).

\begin{tabular}{|c|c|c|c|}
\hline Year & Total & $\begin{array}{l}\text { Unqualified use } \\
\text { of the eponym }\end{array}$ & $\begin{array}{l}\text { \% of total articles on HSD or HSS in } \\
\text { which use of term is unqualified }\end{array}$ \\
\hline $1990-99$ & 80 & 70 & 87.5 \\
\hline $2000-10$ & 198 & 86 & 43.4 \\
\hline 2010 & 30 & 6 & 20.0 \\
\hline 09 & 14 & 4 & 28.6 \\
\hline 08 & 14 & 2 & 14.3 \\
\hline 07 & 12 & 5 & 41.7 \\
\hline 06 & 22 & 7 & 31.8 \\
\hline 05 & 22 & 10 & 45.5 \\
\hline 04 & 12 & 5 & 41.7 \\
\hline 03 & 23 & 12 & 52.2 \\
\hline 02 & 12 & 8 & 66.7 \\
\hline 01 & 22 & 17 & 77.3 \\
\hline 2000 & 15 & 10 & 66.7 \\
\hline 99 & 12 & 11 & 91.7 \\
\hline 98 & 3 & 3 & 100 \\
\hline 97 & 9 & 9 & 100 \\
\hline 96 & 8 & 3 & 37.5 \\
\hline 95 & 8 & 8 & 100 \\
\hline 94 & 9 & 9 & 100 \\
\hline & & & \\
\hline
\end{tabular}




\begin{tabular}{|l|l|l|l|}
\hline Year & Total & $\begin{array}{l}\text { Unqualified use } \\
\text { of the eponym }\end{array}$ & $\begin{array}{l}\text { \% of total articles on HSD or HSS in } \\
\text { which use of term is unqualified }\end{array}$ \\
\hline 93 & 11 & 9 & 81.8 \\
\hline 92 & 10 & 9 & 90 \\
\hline 91 & 4 & 3 & 75 \\
\hline 1990 & 6 & 6 & 100 \\
\hline
\end{tabular}

HSD or HSS - Hallervorden-Spatz Disease or Syndrome 
Table 2. Neurology textbook usage of Hallervorden-Spatz Disease or Syndrome over the past two decades.

\begin{tabular}{|c|c|}
\hline Textbook & HSD or HSS \\
\hline Textbook of clinical neurology, ed 11999 & yes \\
\hline Textbook of clinical neurology, ed 22003 & yes \\
\hline Textbook of clinical neurology, ed 32007 & no \\
\hline Adams and Victor's principles of neurology / ed 5, 1993 & yes \\
\hline $\begin{array}{l}\text { Adams and Victor's principles of neurology / } \\
\text { ed } 6,1997\end{array}$ & yes \\
\hline $\begin{array}{l}\text { Adams and Victor's principles of neurology / } \\
\text { ed 7, } 2001\end{array}$ & yes \\
\hline $\begin{array}{l}\text { Adams and Victor's principles of neurology } \\
\text { ed } 8,2005\end{array}$ & yes \\
\hline $\begin{array}{l}\text { Adams and Victor's principles of neurology / } \\
\text { ed 9,2009 }\end{array}$ & no \\
\hline Bradley, Daroff, Neurology in Clinical Practice, ed. 3, 2000 & yes \\
\hline Bradley, Daroff, Neurology in Clinical Practice, ed. 4, 2004 & no \\
\hline Bradley, Daroff, Neurology in Clinical Practice, ed. 5, 2008 & no \\
\hline Merritt's Neurology, ed 9, 1995 & yes \\
\hline Merritt's Neurology, ed 10, 2000 & yes \\
\hline Merritt's Neurology, ed 11, 2005 & no \\
\hline Merritt's Neurology, ed 12, 2010 & no \\
\hline Greenfield's Neuropathology, ed 6, 1997 & yes \\
\hline Greenfield's Neuropathology, ed 7, 2002 & yes \\
\hline
\end{tabular}




\begin{tabular}{|l|l|}
\hline Textbook & HSD or HSS \\
\hline Greenfield's Neuropathology, ed 8, 2008 & no \\
\hline Brain's Neurology, ed 10, 1993 & yes \\
\hline Brain's Neurology, ed 11, 2001 & yes \\
\hline Brain's Neurology, ed 12, 2009 & no \\
\hline
\end{tabular}

HSD or HSS - Hallervorden-Spatz Disease or Syndrome

1) Textbook of Clinical Neurology, ed. Christopher G. Goetz; 2) Adams and Victor's Principles of Neurology, eds. Allan H. Ropper, Martin A. Samuels; 3) Neurology in Clinical Practice, eds. Walter G. Bradley, Robert B. Daroff, Gerald M. Fenichel, Joseph Jankovic; 4) Merritt's Neurology, eds. Lewis P. Rowland, Timothy A. Pedley; 5) Greenfield's Neuropathology, eds. Seth Love, Davin N. Louis, David W. Ellison; 6) Brain's Diseases of the Nervous System, ed. Michael Donaghy 
Figure Legend:

Figure 1. Julius Hallervorden (1882-1965) (middle), and Hugo Spatz (1888-1969) (right), performing a neuropathological examination, unknown year. Person on the left unidentified. Photo published with permission from the Archiv der Max-PlanckGesellschaft, Berlin-Dahlem.

Figure 2. A test of trend over time indicating a declining trend from 1990-2010 in the unqualified use of the eponyms "Hallervorden-Spatz Syndrome" or "Hallervorden-Spatz Disease" $(\mathrm{p}=0.000)$. 